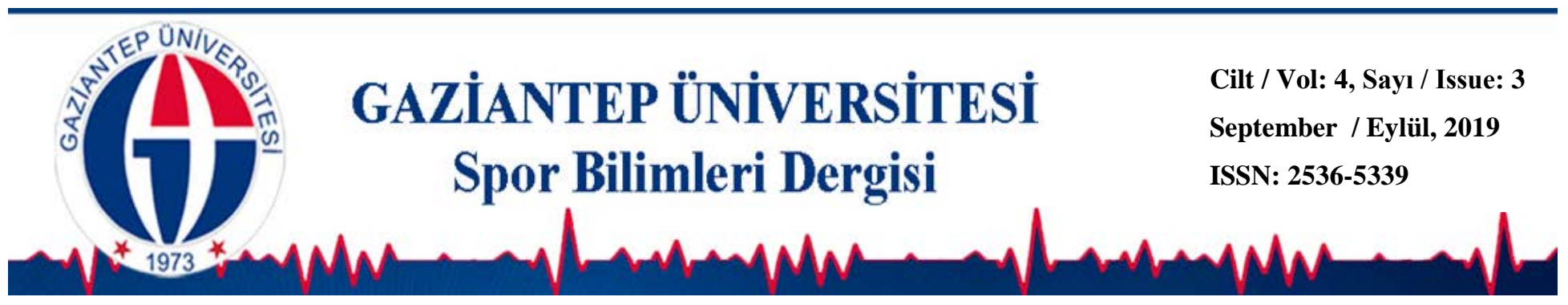

\title{
Kadın ve Erkek Sporcuların İmgeleme Biçimlerinin Karşılaştırılması
}

\author{
Erol DOĞAN ${ }^{1 *}$ (D) \\ ${ }^{1}$ Ondokuz Mayıs Üniversitesi Yaşar Doğu Spor Bilimleri Fakültesi, SAMSUN
}

DOI: 10.31680/gaunjss.605586

Orijinal Makale / Original Article

Geliş Tarihi / Received: 15.08.2019 Kabul Tarihi / Accepted: 04.09.2019 Yayın Tarihi / Published: 22.09.2019

Öz

Bu çalışmanın amacı kadın ve erkek takım sporcularının kullandıkları imgeleme biçimlerinin araştııımasıdır. Çalışmaya 45 futbol, 42 basketbol, 40 voleybol olmak üzere toplam 137 erkek sporcu, 37 futbol, 32 basketbol, 36 voleybol olmak üzere toplam 105 kadın sporcu katılmıştır. Çalışmada veri toplama aracı olarak Halll ve arkadaşları (1998) tarafından geliştirilen ve Kızıldağ ve Tiryaki (2012) tarafından Türkçe'ye uyarlanan Sporda İmgeleme Envanteri kullanılmıştır. Ölçek 21 soru ve 4 alt boyuttan oluşmaktadır. Erkek ve kadınların imgeleme biçimlerinin karşılaştırılmasında t testi, spor yıllarının karşılaştırılmasında ANOVA testi yapılmıştır. Elde edilen sonuçlara göre cinsiyetler arasında imgeleme kullanımı açısından fark yoktur $(p>0,05)$. Benzer şekilde spor yılına bağlı olarak imgeleme biçimleri arasında farklılık yoktur $(p>0,05)$. Bu sonuca göre çalışma grubunun benzer imgeleme biçimlerini kullandığı, bu durumun ortaya çıkmasında aynı seviyede müsabakalara katılımın etkili olduğu söylenebilir.

Anahtar Kelimeler: İmgeleme biçimleri, takım sporcusu, spor

\section{Comparison of Imagery Styles of Female and Male Athletes}

\begin{abstract}
The aim of this study is to investigate the imagery styles used by male and female team athletes. A total of 137 male athletes ( 45 football, 42 basketball, 40 volleyball), and 105 female athletes (37 football, 32 basketball, 36 volleyball) participated in the study. In the study, The Sport Imagery Questionnaire developed by Halll et al. (1998) and adapted to Turkish by Kızıldağ and Tiryaki (2012) was used as data collection tool. The scale consists of 21 questions and 4 sub-dimensions. The t-test was used to compare the imagery styles of men and women, and ANOVA test was used to compare their sports years. According to the results, there is no difference between the genders in terms of the use of imagery $(p>0,05)$. Similarly, there is no difference between imagery styles in terms of sport year $(p>0,05)$. According to this result, it can be said that the study group uses similar imagery and that participation in competitions at the same levels is effective in the emergence of this result.
\end{abstract}

Key Words: Imagery styles, team athletes, sport 


\section{Giriş}

İmgeleme, uzun yıllardır uygulamalı spor psikolojinin araştırma konularından biri olmuştur. Sportif başarının elde edilebilmesi için performansa etki eden unsurların araştırılması önemlidir. İmgeleme kavramı ile ilgili araştırmalar ve araştırmalardan elde edilen sonuçlar uygulamalı spor psikolojisinin gelişimine önemli katkılar sağladığı gibi performans düzeyinde de etkili olmaktadır (Konter, 1999). Günümüzde elit sporcuların üst düzey performans gelişimi için antrenman kapsamı içeriğinde imgeleme çalışmaları yer aldığı da görülmektedir.

Günümüzde antrenör ve sporcuların üzerinde yoğun olarak durduğu konulardan biri sportif performansı geliştirmek için yapılan fiziksel ve psikolojik çalışmalardır. Fiziksel ve psikolojik performansı geliştirmek için bir sürü beceri bulunmaktadır. Bunlardan birisi de imgeleme becerisidir (Kızıldağ ve Tiryaki, 2012).

İmgeleme çalışmalarının geliştirilmesi ve uygulanması spor psikologları tarafından yapılmaktadır ve imgeleme alan olarak mental çalışma sürecinin bir bileşenidir. İmgeleme süreci sadece zihinde bir ifadeyi canlandırma olarak değil, canlandırılan durum ile ilgili olan duyu organları ile ilişkilidir. Bu alanın içinde koku alma, görme, işitme, dokunma, tat alma duyuları bulunmaktadır (Hall ve ark., 1998).

İmgeleme kavramı tanımlanırken zihinsel antrenman ifadesi ile birlikte benzer ifadelerin de kullanıldığı görülmektedir. Bu kavramların içinde sembolik kavramlar, mental, bilişsel süreçler, visiomotor, idiomotorik ve imgesel uygulamalar ifade edilmektedir (Morgan, 1999). Sportif performansın elde edilebilmesi, imgeleme çalışmalarından optimal verim alınabilmesi için zihinsel süreçlerin doğru yönetilmesi gerekir. Bu süreçte olumlu imgelerin kullanılması gerekmektedir. Kullanılan olumlu imgelemeye bağlı olarak sporcular uygulayacakları beceriyi doğru bir şekilde yapabileceklerdir. Sonuç olarak imgeleme yöntemlerinin kullanılması ile sporcuların öğrenme süresinin kısalacağı ifade edilmektedir. Ayrıca imgeleme çalışmaları ile birlikte hareket ve becerinin istenilen seviyede yapılması kolaylaşır, sakatlık oluşma riski azalır ve duygu kontrolünü de sağlanmış olur (Kızıldağ, 2007).

İmgelemenin kişisel gelişim, sosyal alan, eğitim ve mesleki alanda da kullanıldığı ifade edilebilir. Dolaylı olarak iletişim becerilerini etkili olarak kurabilen sporcu, takım içinde de etkili olabilir (Dökmen, 2000).

Sporcuların başarılı olabilmek için çok fazla efor harcadıkları bilinmektedir. Başarıyı ortaya çıkaran unsurlar fizyolojik olabileceği gibi psikolojik faktörler olarak da 
karşımıza çıkmaktadır. Bu psikolojik faktörlerin içinde imgeleme kavramı da yer almaktadır. Erkek ve kadınlar yapıları gereği farklı unsurlar tarafından güdülenebilirler. Erkek sporcu için önemli olan kavram kadın sporcu için önemsiz olabilmektedir. Bu sebeple cinsiyetler arasındaki farklılaşmaya etki edecek unsurların araştırıması önemlidir. Bu amaçla yapılan çalışmada amaç kadın ve erkek takım sporcularının kullandıkları imgeleme biçiminin karşılaştırılmasıdır.

\section{Yöntem}

Çalışmaya 45 futbol, 42 basketbol, 40 voleybol olmak üzere toplam 137 erkek sporcu, 37 futbol, 32 basketbol, 36 voleybol olmak üzere toplam 105 kadın sporcu katılmıştır. Çalışmada veri toplama aracı olarak Halll ve arkadaşları (1998) tarafından geliştirilen ve Kızıldağ ve Tiryaki (2012) tarafından Türkçe'ye uyarlanan Sporda İmgeleme Envanteri kullanılmıştır. Kızıldağ ve Tiryaki (2012) tarafından yapılan Sporda İmgeleme Envanteri kullanılmıştır. Ölçek 21 soru ve 4 alt boyuttan oluşmaktadır. Ölçeğin alt boyutlarını; "Bilişsel İmgeleme", "Motivasyonel Özel İmgeleme", "Motivasyonel Genel Uyarılmışlık" ve "Motivasyonel genel Ustalık" oluşturmaktadır. Bilişsel İmgeleme alt boyutunu 1, 2, 4, 5, 7, 9, 13, 14, 15 sorular, Motivasyonel Özel İmgeleme 3, 6, 8, 10, 20, Motivasyonel genel- Uyarılmışlık 11,12, 17, 19, Motivasyonel Genel- Ustalık 16, 18, 21 sorular oluşturmaktadır.

Bilişsel imgeleme: Bilişsel İmgeleme alt boyutunda bulunan maddeler incelendiğinde becerinin optimal seviyede kullanımı, beceri uygulamasındaki hataların düzeltilmesi, yeni ve farklı stratejiler geliştirilmesi maddeleri yer almaktadır. Ayrıca bilişsel özelliklerin içinde yer alan oyun planlarının öğrenilmesi ve bu planların uygulanmasına yönelik maddeler de bu imgelemenin içinde yer almaktadır. Ayrıca bilişsel imgeleme, özel uygulanması gereken becerilerin doğru bir şekilde uygulanması için kullanılır. Bu tür imgelemeler farklı becerilerde karşımıza çıkmaktadır. Golf vuruşu, voleybolda servis, basketbolda serbest atış, futbolda iç vuruş gibi birbirinden farklı branşlarda kullanıldığı ifade edilebilir (Paivio, 1985). Bilişsel imgeleme kullanımı spora eni başlayan sporcularda görülebildiği gibi üst düzey sporcularda da karmaşık gelen becerilerin öğrenilmesi ve hatırlanmasında kullanılmaktadırlar (Poon ve Rodgers, 2000).

Motivasyonel Özel İmgeleme: $\mathrm{Bu}$ alt boyutu oluşturan maddeler incelendiğinde bu maddelerin özel performans hedeflerini kapsadığı ifade edilebilir. 
Sporcuların kazanma, başarılı olma, iyi performanslarından dolayı tebrik edildiklerini görmeleri, kazanmanın verdiği gurur gibi duygular motivasyonlarını artırmaktadır. Paivio (1985) Motivasyonel Özel İmgeleme ile ilgili ifadesinde sporcuların hedefle ilişkili görevleri (antrenman) devam ettirmede daha başarılı olduklarını belirmiştir. Martin ve Hall (1995) de motivasyonel özel imgelemeyi kullanan golf oyuncularının yeni olmalarına rağmen imgelemeyi kullanmayan diğer gruba göre antrenman programlarını devam ettirmede başarılı olduklarını ifade etmektedirler

Motivasyonel Genel Uyarılmışlık: Bu alt boyutta yer alan maddeler incelendiğinde bu maddelerin sporcuların uyarılmışlık düzeylerini kapsadığı görülmektedir. Bu tür imgelemeyi kullanan sporcular uyarılmışlık düzeylerini kontrol altında tutmaya çalışmaktadırlar. Bu bağlamda kişi duygusal olarak başa çıkma yollarını öğrenebilmektedir. Ayrıca yarışmaya hazırlanma periyodunda ortaya çıkabilecek kaygı duygusunun kontrolü ve uyarılmışıı düzeyinin kontrol edilmesi için bu imgeleme türü kullanılabilir White ve Hardy, 1998).

Motivasyonel Genel Ustalık: Motivasyonel Genel Ustalık alt boyutunda yer alan maddeler değerlendirildiğinde bu maddelerin daha üst seviyede motivasyonel beceriler ile ilgili olduğu ifade edilebilir. Ustalıkla ilgili olan becerilerde motivasyonel genel ustalık imgeleme biçiminin daha fazla kullanıldığı söylenebilir. Sporcunun bilişsel anlamda güçlü ve kontrollü olmasına olanak sağlar (Hall ve ark., 1998). Motivasyonel genel ustalık puanı yüksek sporcuların kendine güvenlerinin fazla olduğu görülmektedir (Munroe ve ark., 2000).

\section{Verilerin Analizi}

Erkek ve kadın sporcuların cinsiyet değişkenine bağlı imgeleme puanlarının karşılaştırımasında $\mathrm{t}$ testi, cinsiyetlerin spor yılına bağlı imgeleme biçimlerinin karşılaştırılmasında One Way ANOVA testi uygulanmıştır.

\section{Bulgular}

Çalışmada elde edilen sonuçlar tablolar halinde sunulmuştur.

Tablo 1. Erkek ve kadınların imgeleme puanlarının karşılaştırılması

\begin{tabular}{|c|c|c|c|c|c|c|}
\hline & & $\mathbf{n}$ & Ort. & S.S. & $t$ & $\mathbf{p}$ \\
\hline \multirow{2}{*}{$\begin{array}{l}\text { Bilişsel } \\
\text { İmgeleme }\end{array}$} & Erkek & 137 & 5,52 & 1,38 & \multirow{2}{*}{1,404} & \multirow{2}{*}{0,162} \\
\hline & Kadın & 105 & 5,29 & 1,02 & & \\
\hline \multirow{2}{*}{$\begin{array}{l}\text { Motivasyonel } \\
\text { Özel İmgeleme }\end{array}$} & Erkek & 137 & 5,42 & 1,27 & \multirow{2}{*}{1,314} & \multirow{2}{*}{0,190} \\
\hline & Kadın & 105 & 5,20 & 1,33 & & \\
\hline
\end{tabular}


Doğan E., (2019). Kadın ve Erkek Sporcuların İmgeleme Biçimlerinin Karşılaştırılması. Gaziantep Üniversitesi Spor Bilimleri Dergisi, 4(3), 373-381.

\begin{tabular}{|c|c|c|c|c|c|c|}
\hline \multirow{2}{*}{$\begin{array}{l}\text { Motivasyonel } \\
\text { Genel } \\
\text { Uyarılmışlık }\end{array}$} & Erkek & 137 & 4,79 & 1,37 & \multirow{2}{*}{$-1,946$} & \multirow{2}{*}{0,053} \\
\hline & Kadın & 105 & 5,20 & 1,92 & & \\
\hline \multirow{2}{*}{$\begin{array}{l}\text { Motivasyonel } \\
\text { Genel Ustalık }\end{array}$} & Erkek & 137 & 5,66 & 1,15 & \multirow{2}{*}{0,254} & \multirow{2}{*}{0,800} \\
\hline & Kadın & 105 & 5,62 & 1,17 & & \\
\hline
\end{tabular}

Erkek ve kadınların imgeleme puanları arasında fark yoktur $(p>0,05)$.

Tablo 2. Erkeklerin spor yılının karşılaştırılması

\begin{tabular}{|c|c|c|c|c|c|c|c|}
\hline & & & $n$ & Ort. & S.S. & $F$ & $p$ \\
\hline \multirow{12}{*}{ Erkek } & \multirow{3}{*}{$\begin{array}{c}\text { Bilişsel } \\
\text { İmgeleme }\end{array}$} & 1-4 yıl & 42 & 5,61 & 1,60 & \multirow{3}{*}{,216 } & \multirow{3}{*}{806} \\
\hline & & $5-9 \mathrm{yll}$ & 52 & 5,52 & 1,59 & & \\
\hline & & 10 yıl ve üzeri & 43 & 5,42 & 0,75 & & \\
\hline & \multirow{3}{*}{$\begin{array}{l}\text { Motivasyonel } \\
\text { Özel İmgeleme }\end{array}$} & $1-4 \mathrm{yll}$ & 42 & 5,53 & 1,45 & \multirow{3}{*}{,220 } & \multirow{3}{*}{,803 } \\
\hline & & $5-9$ yıl & 52 & 5,37 & 1,22 & & \\
\hline & & 10 yıl ve üzeri & 43 & 5,38 & 1,14 & & \\
\hline & \multirow{3}{*}{$\begin{array}{c}\text { Motivasyonel } \\
\text { Genel } \\
\text { Uyarılmışlık }\end{array}$} & $1-4 \mathrm{yll}$ & 42 & 5,00 & 1,42 & \multirow{3}{*}{,772 } & \multirow{3}{*}{,46 } \\
\hline & & $5-9$ yıl & 52 & 4,65 & 1,46 & & \\
\hline & & 10 yıl ve üzeri & 43 & 4,74 & 1,20 & & \\
\hline & \multirow{3}{*}{$\begin{array}{l}\text { Motivasyonel } \\
\text { Genel Ustalık }\end{array}$} & 1-4 yıl & 42 & 5,58 & 1,39 & \multirow{3}{*}{ 267 } & \multirow{3}{*}{,766 } \\
\hline & & $5-9$ yıl & 52 & 5,65 & 1,11 & & \\
\hline & & 10 yıl ve üzeri & 43 & 5,76 & 0,92 & & \\
\hline
\end{tabular}

Erkeklerin spor yılı karşılaştırıldığında gruplar arasında fark yoktur $(p>0,05)$.

Tablo 3. Kadınların spor yılııın karşılaştıııması

\begin{tabular}{|c|c|c|c|c|c|c|c|}
\hline & & & $\mathrm{n}$ & Ort. & S.S. & $F$ & $p$ \\
\hline \multirow{12}{*}{ Kadın } & \multirow{3}{*}{$\begin{array}{l}\text { Bilişsel } \\
\text { Imgeleme }\end{array}$} & 1-4 yıl & 38 & 5,35 & 0,94 & \multirow{3}{*}{,502 } & \multirow{3}{*}{ 607, } \\
\hline & & $5-9$ yıl & 40 & 5,17 & 1,13 & & \\
\hline & & $\begin{array}{c}10 \text { yıl ve } \\
\text { üzeri }\end{array}$ & 27 & 5,40 & 0,95 & & \\
\hline & \multirow{3}{*}{$\begin{array}{c}\text { Motivasyonel } \\
\text { Özel } \\
\text { İmgeleme }\end{array}$} & $1-4$ yıl & 38 & 5,19 & 1,37 & \multirow{3}{*}{ 389 } & \multirow{3}{*}{ 679, } \\
\hline & & $5-9 \mathrm{yll}$ & 40 & 5,09 & 1,36 & & \\
\hline & & $\begin{array}{c}10 \text { yıl ve } \\
\text { üzeri }\end{array}$ & 27 & 5,38 & 1,23 & & \\
\hline & \multirow{3}{*}{$\begin{array}{c}\text { Motivasyonel } \\
\text { Genel } \\
\text { Uyarılmışlık }\end{array}$} & $1-4$ yıl & 38 & 4,89 & 0,97 & \multirow{3}{*}{1,645} & \multirow{3}{*}{ 198 } \\
\hline & & $5-9$ yıl & 40 & 5,12 & 1,23 & & \\
\hline & & $\begin{array}{c}10 \text { yıl ve } \\
\text { üzeri }\end{array}$ & 27 & 5,75 & 3,27 & & \\
\hline & \multirow{3}{*}{$\begin{array}{l}\text { Motivasyonel } \\
\text { Genel Ustalık }\end{array}$} & $1-4$ yıl & 38 & 5,57 & 1,33 & \multirow{3}{*}{ 707, } & \multirow{3}{*}{ 495 } \\
\hline & & $5-9$ yıl & 40 & 5,52 & 1,11 & & \\
\hline & & $\begin{array}{c}10 \text { yıl ve } \\
\text { üzeri }\end{array}$ & 27 & 5,85 & 1,01 & & \\
\hline
\end{tabular}

Kadınların spor yılı karşılaştırıldığında gruplar arasında fark yoktur $(p>0,05)$.

\section{Tartışma ve Sonuç}

İmgeleme çalışmaları günümüzde spor bilimleri alanında yerini almaktadır. Beceri veya bir taktiğin geliştirilmesinde kullanılabildiği gibi farklı bilişsel durumlar için 
de kullanılmaktadır. Aldemir ve ark. (2014), yaptıkları çalışmada imgeleme çalışmaları yapan futbolcuların problem çözme becerilerinde artış olduğunu ifade etmiştir.

Kadın ve erkek takım sporcularının imgeleme biçimlerinin karşılaştırıldığı çalışmada cinsiyetler arası farklılık tespit edilmemiştir ( $p>0,05)$. Hall (2001) imgeleme kullanımında oyun stratejileri, planların uygulanması, beceri gelişimi, hareket serilerinin yapılması ve geliştirilmesini içeren bilişsel imgeleme kavramından bahsetmiştir. Motivasyonel genel uyarılmışlık biçimi ise bir sporcu yarışmaya hazırlanırken stres ve hazır bulunuşluk durumuyla ifade edilmektedir (Munroe, 2006). Motivasyonel genel ustalık imgeleme becerisini kullanan sporcuların ise yüksek kendine güvenleri olduğu ve benlik algılarının da bu oranda arttığı ifade edilmektedir (Hall ve ark., 1998; Munroe ve ark., 2000).

Parker ve Lovell (2012) imgeleme biçimlerinin yaş grupları arasındaki farklılığa olan etkilerini araştırmış; 20-21 yaş grubu sporcunun 12-13 yaş grubu sporculardan daha yüksek imgeleme puanına sahip olduklarını ortaya koymuştur. Kartal ve ark., (2017), yaptıkları çalışmada yaş grupları ile imgeleme arasındaki farkılığı incelemişlerdir. Motivasyonel genel ustalık alt boyutunda anlamlı farklılık olduğunu ifade etmişlerdir. Yapılan çalışmada cinsiyet değişkenine bağlı farklılık oluşmaması çalışma gruplarının benzer antrenman seviyesine sahip olması etki etmiş olabilir. Roberts ve ark., (2008) yarışma düzeyinin imgeleme biçimlerine etki edebileceğini belirtmiştir. Çalışma grubunun benzer yarışma seviyesinde olması elde ettiğimiz sonuçların ortaya çıkmasına etki etmiş olabilir.

Krista ve ark. (2000), imgeleme antrenmanlarım nasıl ve nerde yapıldığını araştırmışlardır. Araştırma kapsamında 7 farklı branştan 7 erkek 7 bayan elit sporcu üzerinde çalışılmış, sporcuların hayal etmeyi beceri öğreniminden çok daha iyi performans sergilemek ve performanslarını arttırmak için kullandıklarını belirtmişlerdir. Aldemir ve ark. (2014) elit futbolcularda yaptıkları çalışmada imgeleme çalışmalarının benlik saygılarında artış olduğunu ifade etmiştir.

Farklı branşlara ait yapılan çalışmalarda imgeleme kullanım biçimlerinin değişiklik gösterdiği ifade edilmektedir. Yamak ve ark. (2018) kadın basketbolcuların spor yılına göre imgeleme biçimini araştırmış, 14 yıl ve üzeri olan sporcuların farklı imgeleme biçimi kullandığını ifade etmiştir. 
Çalışmada elde edilen bir diğer sonuç ise spor yılına bağlı olarak kullanılan imgeleme biçimleri arasında farklılık olmamasıdır ( $p>0,05)$. Erdoğan (2009) yaptığı çalışmada spor yılı ile imgeleme puanları arasında bir ilişki olmadığını ifade etmiştir. Smith ve ark. (2007) farklı iki imgeleme metoduyla yaptıkları çalışmada iki çalışma yönteminin de gelişim sağlamaya yardımcı olduğunu ifade etmiştir.

Nordin ve ark. (2006) üç farklı yarışma grubundaki sporcuların kullandıkları imgeleme biçimlerini karşılaştırmıştır. Çalışmaya üst düzey, orta düzey ve rekreasyon amaçlı yarışan sporcular dahil edilmiştir. Çalışma sonunda üst düzey performans gösteren sporcuların imgeleme biçimlerini daha fazla kullandıklarını ifade etmişlerdir. Bu çalışma sonucu elde ettiğimiz bulguları destekler niteliktedir. Çalışma gruplarının benzer özelliklere sahip olması farklılığın oluşmasına veya oluşmamasına etki edebilir.

$\mathrm{Bu}$ çalışma sonucuna göre sporcuların cinsiyetinden ziyade oyunculuk seviyelerinin imgeleme biçimlerine etki edebileceği söylenebilir. Sporculara uygulanacak olan imgeleme çalışmalarının sporcularının seviyelerine uygun olması önerilmektedir.

\section{Kaynaklar}

Aldemir, G.Y., Biçer, T., \& Kale, E.K. (2014). Elit futbolcularda imgeleme çalışmalarının benlik algısı üzerine etkisi. СBÜ Beden Eğitimi ve Spor Bilimleri Dergisi, 6(1), 1-15.

Dökmen, Ü. (2000). İletişim Çatışmaları ve Empati. Sistem Yayıncılık. 14. Baskı. İstanbul.

Erdoğan, D.P. (2009). Bireysel ve takım sporlarılla uğraşan sporcuların hayal etme ve kaygı düzeylerinin karşılaştırılması. Yüksek Lisans Tezi, Sakarya Üniversitesi, Sosyal Bilimler Enstitüsü, Sakarya.

Folkmann, M. N. (2010). Enabling creativity imagination in design processes. 1st International Conference on Design Creativity.

Kartal, Z., Güvendi, B., Türksoy, A., \& Altıncı, E. E. (2017). Takım Sporcularının İmgeleme Kullanımları İle Başari Motivasyonları Arasındaki İlişki. İstanbul Üniversitesi Spor Bilimleri Dergisi, 7(1), 41-53. 
Hall, C. R., Mack, D. E., Paivio, A., \& Hausenblas, H. A. (1998). Imagery use by athletes: development of the Sport Imagery Questionnaire. International Journal of Sport Psychology. 29, 73-89.

Hall, C. R. (2001). Imagery in sport and exercise. Handbook of sport psychology, 2, 529-549.

Kızıldağ, E (2007). Farklı spor branşlarındaki sporcuların imgeleme biçimleri. Mersin Üniversitesi, Sağlık Bilimleri Enstitüsü, Yüksek Lisans Tezi, Mersin.

Kızıldağ, E., \& Tiryaki, M. Ş. (2012). Sporda imgeleme envanterinin türk sporcular için uyarlanması. Spor Bilimleri Dergisi, 23(1), 13-23.

Krista, J. M., Giacabbi, P. R., Hall, C., Weinberg, R. S. (2000). The four ws of imagey use: where, when, why and what. The Sport Psychologist, 14 (2), 119-137.

Konter, E. (1999). Uygulamali Spor Psikolojisinde Zihinsel Antrenman. Nobel yayın dağıtım, Ankara.

Munroe, K. J., Giacobbi, P. R., Hall, C., \& Weinberg, R. (2000). The four Ws of imagery use: Where, when, why, and what. The Sport Psychologist, 14(2), 119-137.

Martin, K. A., \& Hall, C. R. (1995). Using mental imagery to enhance intrinsic motivation. Journal of Sport and Exercise Psychology, 17(1), 54-69.

Morgan, C. T. (1999). Psikolojiye giriş (Çeviren: S. Karakaş). Ankara: Hacettepe Psikoloji:

Munroe, K., Giacobbi, P., Hall, C., Weinberg, R. (2000). The fourW's of imageryuse: Where, when, why, andwhat. The SportPsychologist, 14, 119-137.

Nordin, S. M., Cumming, J., Vincent, J., \& McGrory, S. (2006). Mental practice or spontaneous play? Examining which types of imagery constitute deliberate practice in sport. Journal of Applied Sport Psychology, 18(4), 345-362.

Paivio, A. (1985). Cognitive and motivational functions of imagery in human performance. Canadian Journal of Applied Sport Sciences, 10(4), 22- 28.

Parker, J. K., \& Lovell, G. P. (2012). Age differences in the vividness of youth sport performers' imagery ability. J Imagery Res Sport Phys Activ. 7(1), 1-13.

Poon, P. P., \& Rodgers, W. M. (2000). Learning and remembering strategies of novice and advanced jazz dancers for skill level appropriate dance routines. Research Quarterly for Exercise and Sport, 71(2), 135-144. 
Roberts, R., Callow, N., Hardy, L., Markland, D., \& Bringer, J. (2008). Movement imagery ability: development and assessment of a revised version of the vividness of movement imagery questionnaire. Journal of Sport and Exercise Psychology, 30(2), 200-221.

Smith, D., Wright, C., Allsopp, A., \& Westhead, H. (2007). It's all in the mind: PETTLEP-based imagery and sports performance. Journal of Applied Sport Psychology, 19(1), 80-92.

White, A., \& Hardy, L. (1998). An in-depth analysis of the uses of imagery by highlevel slalom canoeists and artistic gymnasts. The Sport Psychologist, 12(4), 387-403.

Yamak, B., Mehmet, Çebil., Eliöz, M., Küçük, H., \& Ceylan, L. (2018). The Comparison Of Imagery Levels According To Sport Age in Female Basketball Players. The Journal of International Anatolia Sport Science, 3(1), 274-280. 